\title{
Effect of Graphite on The Pervaporation Performance of Silicone Rubber Membranes
}

\author{
P.S. Sarath ${ }^{1}$, RintuJacob ${ }^{1}$, Thomasukutty Jose ${ }^{1}$, Józef T. Haponiuk ${ }^{2}$, Sabu Thomas ${ }^{3}$ and \\ Soney C. George ${ }^{1, *}$
}

${ }^{1}$ Centre for Nanoscience and Technology, Amal Jyothi College of Engineering, Kanjirappally, Kottayam, Kerala, India

${ }^{2}$ Department of Polymer Technology, Gdansk University of Technology, Gdańsk, Poland

${ }^{3}$ International and Inter University Centre for Nanoscience and Nanotechnology, Mahatma Gandhi University, Kottayam, Kerala, India

\begin{abstract}
Pervaporation process is a membrane based separation process. Polymer membranes were widely used for separating liquid mixtures using pervaporation process. In this study, composite membranes were prepared by mixing natural graphite (NG) and silicone rubber (QM) using two roll mill. Synthesized composite membrane was used for the separation process. The composite membrane reveals the impressive separation performance of methanol - toluene mixtures with preferential selectivity towards methanol. $10 \mathrm{phr}$ (parts per hundred) natural graphite filled membrane obtained best flux and $15 \mathrm{phr}$ membrane showed better selectivity. Optimal separation performance with the permeation flux of $386 \%$ and separation factor 1.5 times compared to QM control membrane is obtained. The study confirmed that increasing toluene feed concentration improved the selectivity of membranes.
\end{abstract}

Keywords: Pervaporation, Graphite, Silicone rubber, Methanol, Toluene.

\section{INTRODUCTION}

Pervaporation (PV) has been used as an effective membrane technique for separating azeotropic mixtures, heat sensitive compounds and close boiling point liquids. This method used for the separation of water from organic solvents and their mixtures and separation of liquid organic mixtures [1-3]. The advantages of $\mathrm{PV}$ are, it can be carried out at low temperature and the reusage of membrane with minimum environmental emission of the treated chemicals. Thus, in terms of energy and material consumption as well as environmental emission, PV is an ideal example of process intensification. This technique mainly used for the dehydration of organics using hydrophilic membrane or from the removal of organic using organophilic membranes [4-5]. However, for the separation of organic-organic mixtures neither of these membranes can be used. It requires suitable membrane selectivity based on the closeness of solubility parameter value of the permeate with membrane material [6]. It is the only membrane process in which a phase transition occurs during transport through a dense or microporous matrix. The phase transition occurs due to the vacuum at the permeate side. Selectivity is obtained by selective dissolution of components from a liquid mixture in the

"Address correspondence to this author at the Centre for Nanoscience and Technology, Amal Jyothi College; Tele: +919447870319;

E-mail: soneygeo@gmail.com membrane material and the differences in diffusion through the membrane. This allows separation of solvents on the basis of their affinity for the membrane material, in contrast to classical distillation where separation occurs as a result of differences in volatility. Thus, azeotropic mixtures and mixtures with a relative volatility close to one can be separated by pervaporation, on condition that they have a clear difference in properties determining their transport through pervaporation membranes. Silicon rubber coated on different membranes improved their separation efficiency and selectivity [7-8]. Addition of solid filler on polymer can remarkably improve the solubility property through the preferential adsorption, which results in the increase of separation factor and decrease of permeation flux [9].

Graphite filler is suitable for the separation of toluene-methanol mixtures because of the hexagonal arrangement of carbon atoms similar to that of benzene ring and the $\pi-\pi$ bonds interaction between the planes allowing interaction with electron clouds of toluene. Lopez et al. [10]. Investigated the specific interactions between aromatic electrons of organic compounds and graphite surfaces as detected by immersion calorimetry.

The pervaporation separation of methanol/toluene and ethanol/toluene mixtures investigated by Park et al. [11-12] using the blend membranes of poly(acrylic acid) 
(PAA) and poly(vinyl alcohol) (PVA). It was found that alcohols permeated preferentially through these membranes. The flux decreased gradually as the PVA content of the blend increased, whereas selectivity increased. Literature shows that in most of the organicorganic separations glassy membranes have been used. Duval et al. [13] investigated separation of toluene/ethanol mixtures by pervaporation, using adsorbent-filled membranes by various activated carbons. For all the carbons tested, total flux through the membrane decreased drastically with the addition of the active carbon particles; however, the porous structure of carbon seemed to have no effect on selectivity. The rubbery membranes gives high flux but poor selectivity due to its amorphous structures and hence presence of appreciable amount of free volume in the bulk of the elastomeric chains. Natural rubber and SBR membrane has been used [14] for separation of toluene-methanol mixtures with preferential toluene permeation through these rubbery membranes. A large amount of researches had been reported about silicone rubber with or without silica [15-17], and series of silicone rubber compound membranes [18-19] had been reported for butanol recovery. Dashti et al. studied molecular dynamics and artificial intelligence knowledge of ANFIS to investigate water-acetic acid pervaporation (PV) separation through poly vinylalcohol (PVA)/silicone based membranes under a wide range of experimental condition [20]. Rezakazemi et al. studied Polydimethylsiloxane (PDMS) membranes supported on cellulose acetate (CA) and polyamide (PA) microfiltration membranes on the effects of support layer and permselective thickness on the separation performance of membranes at different operating conditions [21]. Shahverdi et al. studied Poly(vinyl alcohol) (PVA)/zeolite 4A mixed matrix composite membranes supported on polypropylene microfiltration membranes were prepared by solution casting method and crosslinked with glutaraldehyde to investigate their pervaporation (PV) separation properties of water-ethylene glycol mixtures [22]. However, the selective removal of methanol from anhydrous organic liquid mixtures is required in many applications. Silicone rubber /graphite membranes were not used for the selective separation of methanol from toluene-methanol mixtures.

In this study, we developed QM- graphite membrane material with different graphitic contents and which was used for the separation of methanol from toluene-methanol mixture over the concentration range of $10-90 \mathrm{wt} \%$ methanol. The effects of graphite concentration and feed composition on flux and selectivity have also been estimated.

\section{MATERIALS}

Silicone rubber 5060-U GP-301 (HTV) (Dow Corning Co.; dimethyl, methyl vinyl siloxane dimethyl vinyl terminated $(>60 \%)$, DCP (Dicumyl Peroxide) curing agent and graphite were procured from Sigma Aldrich, Banglore, India. Other compounding ingredients and solvents were used as laboratory grade without further purification.

\section{EXPERIMENTAL PART}

\subsection{Preparation $Q M / G r a p h i t e$ Membrane}

\subsubsection{Compounding of Mixes}

\section{Composite Preparation}

Graphite filled Silicone rubber and unfilled membranes were prepared. The mixing was done on a laboratory scale Two roll mill. The temperature of the rolls kept constant at $28^{\circ} \mathrm{C}$. First rubber was masticated for 2 minutes and then graphite and followed by DCP added one by one and the mixing was completed within

Table 1: Formulation of Mixes in Phr*

\begin{tabular}{|c|c|c|c|}
\hline Membrane & Weight of QM & Weight of graphite & DCP \\
\hline \hline QM & 100 & 5 & 1.5 \\
\hline QMG 5 & 100 & 10 & 1.5 \\
\hline QMG 10 & 100 & 15 & 1.5 \\
\hline QMG 15 & 100 & 20 & 1.5 \\
\hline QMG 20 & 100 & 30 & 1.5 \\
\hline
\end{tabular}

*Parts per hundred rubber. 


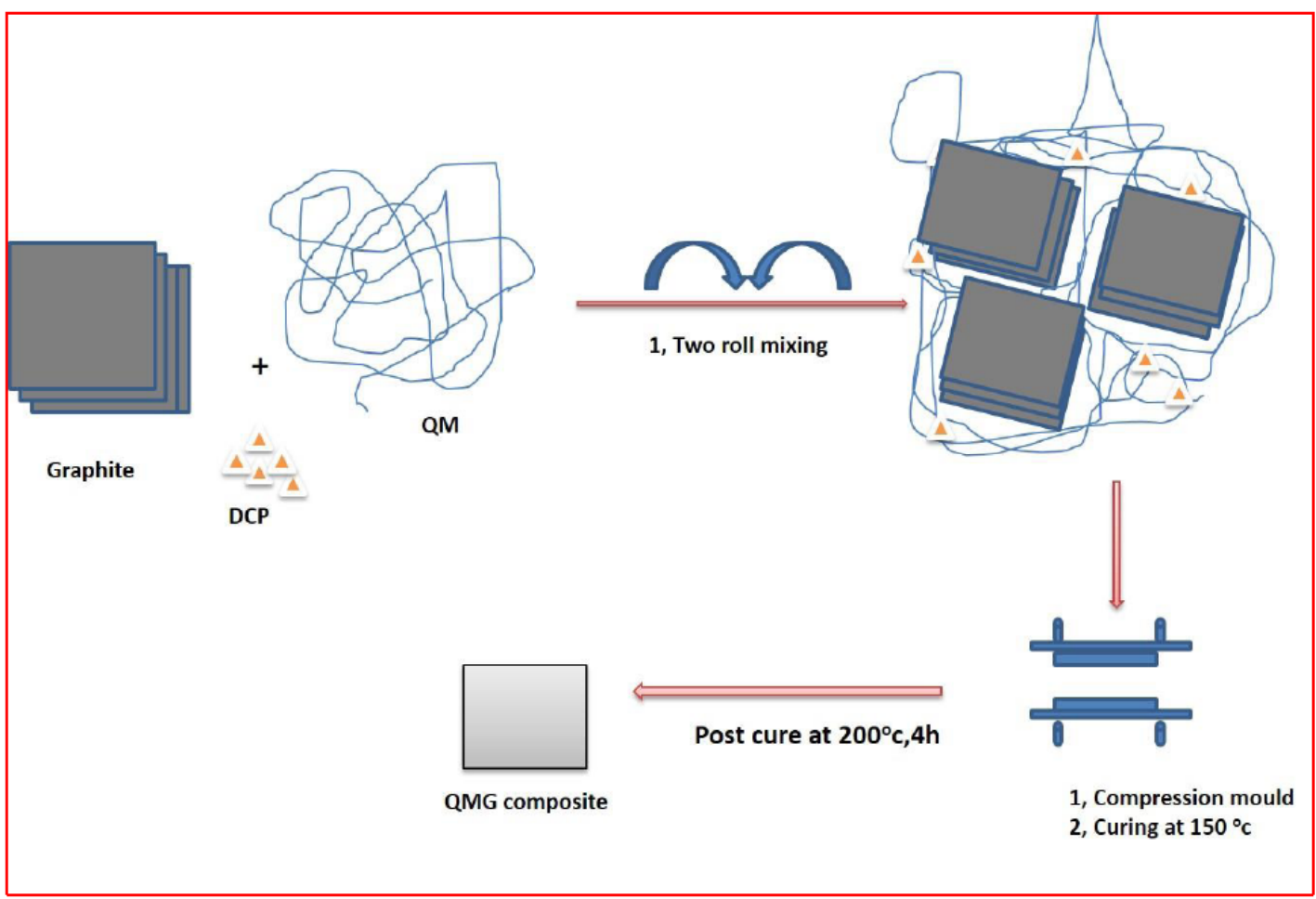

Figure 1: Schematic representation of preparation of QMG composite membrane.

20 minutes. Cure characteristics of the samples were determined using a Moving Die rheometer at a temperature of $150^{\circ} \mathrm{C}$. Thin films of the pervaporation samples moulded using an electrically heated hydraulic press under a pressure of 150 bars at $150^{\circ} \mathrm{C}$. Different contents $(0,5,10,15,20,30)$ of graphite filled membranes were prepared and these membranes are represented as QM, QMG 5, QMG 10, QMG 15, QMG 20, QMG 30. Schematic representation of preparation of composite membranes are shown in Figure 1.

\subsubsection{Pervaporation Studies}

The pervaporation experiments were performed with the effective area of the membrane in contact with feed solution was $16.61 \mathrm{~cm}^{2}$. The membrane was first swelled in the organic mixture to be separated and then mounted in the cell. The vacuum was then pumped out on the downstream side. Feed solution is introduced into the upper part of membrane which is maintained at atmospheric pressure. The membrane was kept in the pervaporation cell for about $1 \mathrm{~h}$ in each run to reach equilibrium conditions before collecting the permeate. Once steady state was reached permeate was collected in traps immersed in liquid nitrogen. The flux was calculated by weighing permeate on a digital microbalance Mettler Toledo (JB1603-C/FACT) with an accuracy $\pm 0.0001 \mathrm{~g}$. The feed and permeate compositions of all of the mixtures were determined by measuring their refractive indices with a refractometer. All the experiments were carried out at room temperature and were repeated to obtain reproducible results and the errors inherent in the pervaporation measurements were less than $1.0 \%$. Separation performances of the membranes can be evaluated on the basis of total flux $(J)$ and separation factor $(\alpha)$. Schematic representation of pervaporation setup is given in Figure 2.

The pervaporation performance of the QMG membranes were evaluated by the separation factor $(\alpha)$, and the separation flux $(J)$ by the following expressions

$\alpha=\left(\frac{Y a}{Y b}\right) /\left(\frac{X a}{X b}\right)$

$Y_{a}$ and $Y_{b}$ represent the composition of the more permeating component (methanol) and less permeating component ( toluene) in the permeate and $X_{a}$ and $X_{b}$ are those of more permeating component and less permeating component in the feed respectively.

$$
J=Q / A t
$$

$\mathrm{J}$ is the molar flux of the membrane in $\mathrm{kg} \mathrm{m}^{-2} \mathrm{~h}^{-1}, \mathrm{Q}$ is the quantity of permeate in kilograms, $A$ is the 


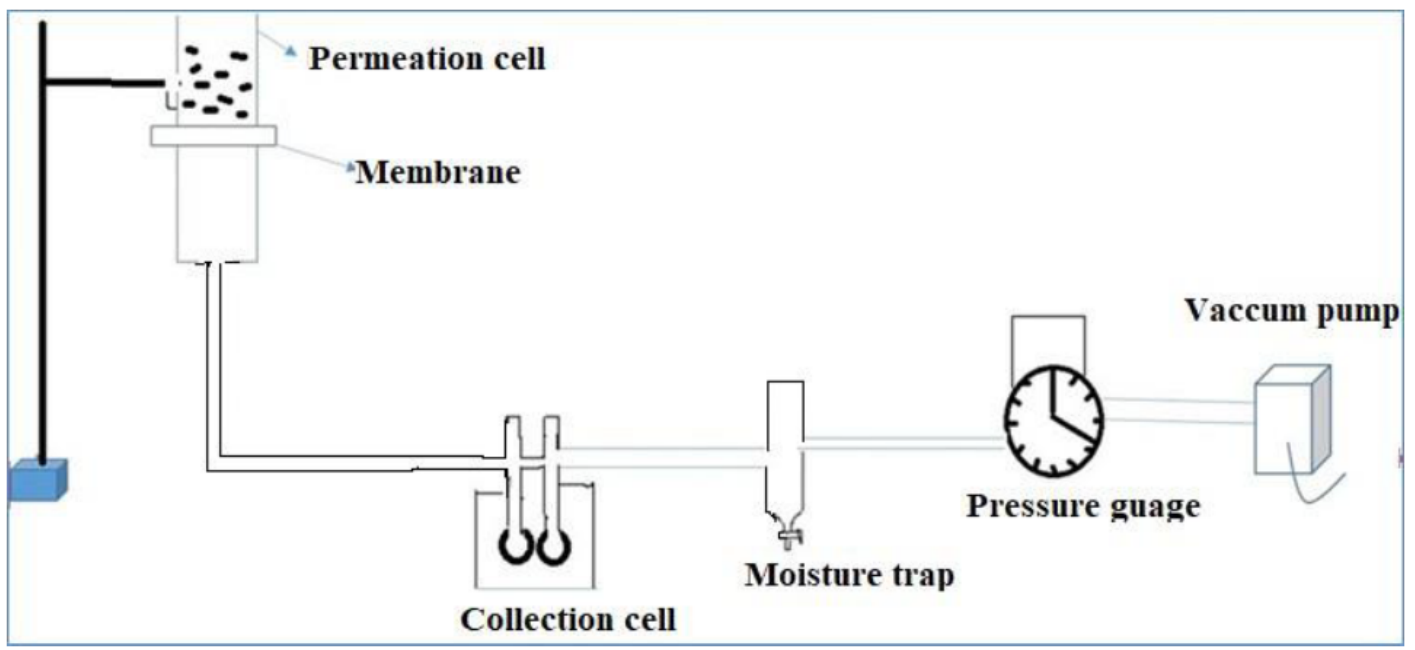

Figure 2: Schematic representation of pervaporation experiment.

effective area of the membrane in $\mathrm{m}^{2}$ used for separation, $\mathrm{t}$ is time in hours.

\section{RESULTS AND DISCUSSIONS}

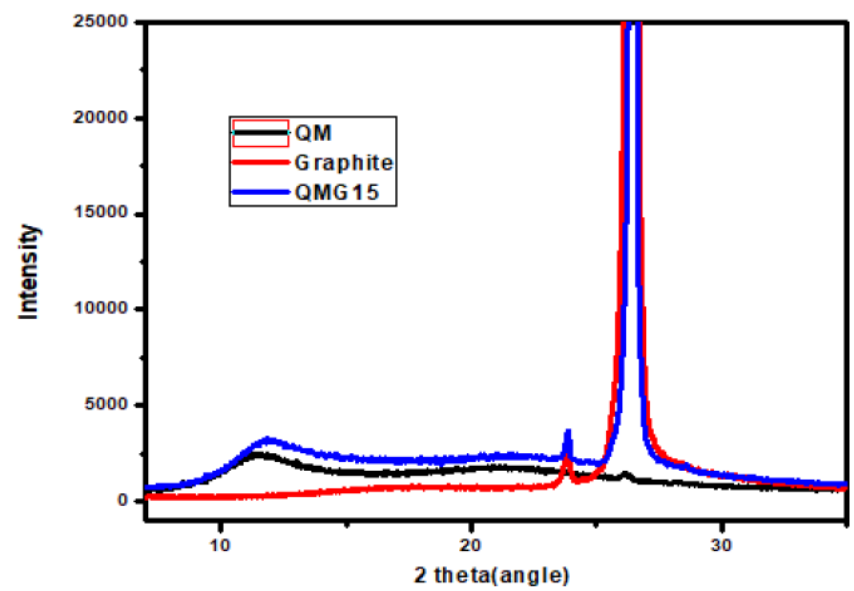

Figure 3: XRD spectrum of QM, graphite and QMG15.

X-ray diffraction patterns of the membranes are shown in Figure 3 It is interesting to note that crystalline peak of graphite is observed at $2 \theta=26.4^{\circ}$ but there is no significant change in this peak. The pure QM membrane exhibits an amorphous peak at $2 \theta=$ $11.28^{\circ}$ and peak become broader with the introduction of graphite in the silicone matrix. This implied that silicone polymer chains are enter into the graphite layers and thereby there is better interaction between graphite and silicone rubber chains.

\subsection{Pervaporation}

\subsubsection{Effect of Filler Loading}

In the present study, a novel membrane based on silicone rubber and graphite is used for separating Toluene/Methanol mixture (10/90 wt \%).

Table 2 shows the effect of graphite concentration on the pervaporation characteristics of QM/Graphite composites. The affinity of membrane towards toluene is the major factor for the separation of methanol and toluene. With increasing the graphite content, flux increases and reaches a maximum at $10 \mathrm{phr}$ of graphite (QMG 10) and then decreases. The variation

Table 2: Variation of Flux, Separation Factor, and Component flux with Graphite Loading

\begin{tabular}{|c|c|c|c|c|c|c|}
\hline Membrane & Permeate Composition & Flux (J) & Separation Factor ( $\mathbf{\alpha})$ & PSI J( $\boldsymbol{\alpha}-\mathbf{1})$ & $\mathbf{J}_{\text {Toluene }}$ & $\mathbf{J}_{\text {Methanol }}$ \\
\hline \hline QM & $8.5 / 91.5$ & 0.00373 & 1.1960 & 0.0007 & 0.0317 & 0.3413 \\
\hline QMG 5 & $6.1 / 93.9$ & 0.0075 & 1.7103 & 0.0053 & 0.0458 & 0.7042 \\
\hline QMG 10 & $7.9 / 92.1$ & 0.0144 & 1.2953 & 0.0043 & 0.1138 & 1.3262 \\
\hline QMG 15 & $5.8 / 94.2$ & 0.00400 & 1.8045 & 0.0032 & 0.0232 & 0.3768 \\
\hline QMG 20 & $7.9 / 92.1$ & 0.00355 & 1.2953 & 0.0010 & 0.0280 & 0.3269 \\
\hline QMG 30 & $9.1 / 90.9$ & 0.00801 & 1.1098 & 0.0009 & 0.0729 & 0.7281 \\
\hline
\end{tabular}


of flux with increase in concentration of graphite is illustrated in Figure 4. The flux of pure silicone rubber membrane is $0.00373 \mathrm{~kg} / \mathrm{m}^{2} \mathrm{~h}$. Thus QM with $10 \mathrm{wt} \%$ graphite membrane shows a maximum enhancement for flux compared to other composite membranes (0.0144).

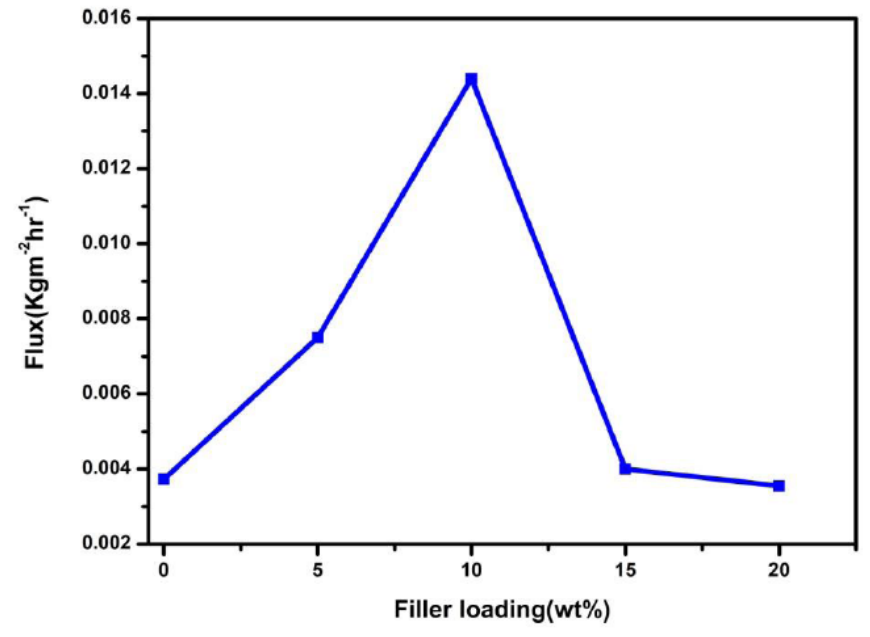

Figure 4: Effect of concentration of graphite on flux.

Separation factor is also increases with increase in graphite content and reaches a maximum at $15 \mathrm{phr}$ of graphite (QMG15) and then decreases [Table 2]. Thus QMG15 composite membrane shows the highest separation factor and QMG10 membrane obtained highest flux. From the table it is clear that there is an optimum concentration of graphite where membrane separation and flux maximum.

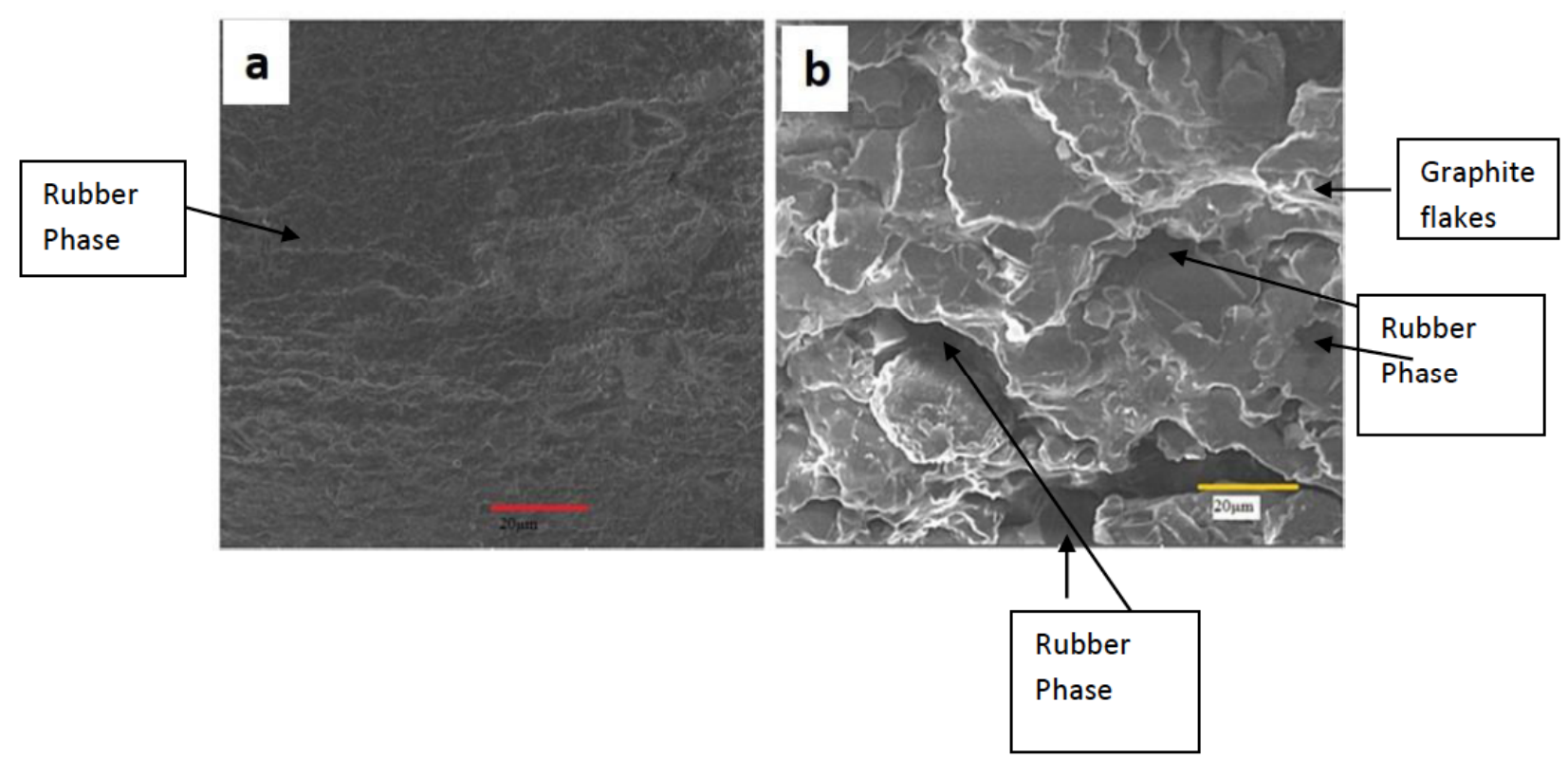

Scanning electron micrographs of cryogenically fractured cross sections of QM and QMG15 membranes were obtained and are shown in in Figure 5. A uniform surface morphology is observed for silicone rubber as in Figure 5(a). Even distribution of graphite flakes are observed in QMG15 membrane as in Figure 5(b). Silicone rubber chains are enter into the expanded graphite flakes and dispersed surface morphology is formed. This helps in the selective movement of methanol through the composite membrane.

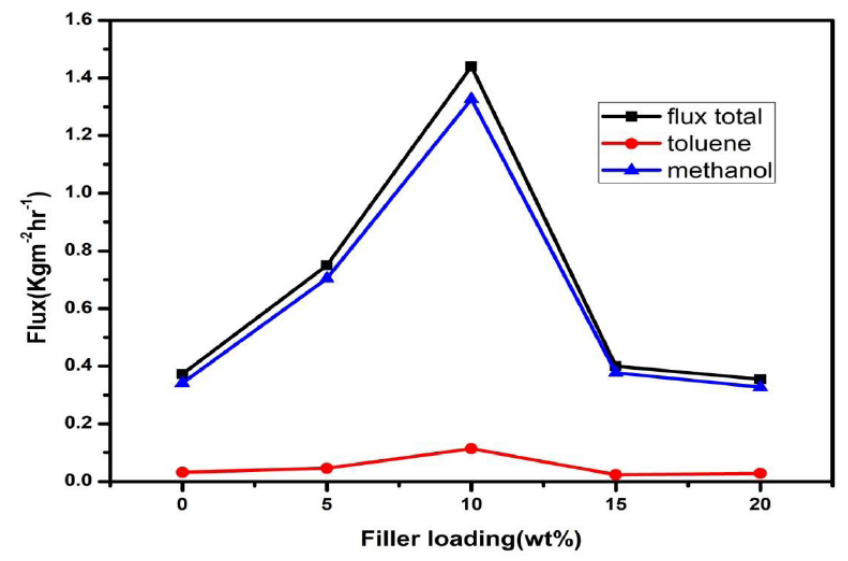

Figure 6: Variation of component flux with filler loading.

Figure 6 shows the variation of component flux with graphite concentration. It is evident from the graph that methanol flux is higher than toluene flux and both exhibit the maximum at $10 \mathrm{phr}$ of graphite loading. So methanol flux is actually contributing towards the total

Figure 5: The SEM micrographs of (a) QM and (b) QMG15 membrane cross-section. 
Table 4: Variation of Flux, Separation Factor, and Component Flux with Feed Composition

\begin{tabular}{|c|c|c|c|c|c|c|}
\hline Feed Composition & Permeate Composition & Flux (J) & Separation Factor ( $\boldsymbol{\alpha})$ & PSI & $\mathbf{J}_{\text {Toluene }}$ & $\mathbf{J}_{\text {Methanol }}$ \\
\hline \hline $10 / 90$ & $5.8 / 94.2$ & 0.004 & 1.8045 & 0.0032 & 0.0232 & 0.3768 \\
\hline $30 / 70$ & $9.8 / 90.2$ & 0.0007 & 3.9446 & 0.0022 & 0.0075 & 0.0694 \\
\hline $50 / 50$ & $8.5 / 91.5$ & 0.0089 & 10.764 & 0.0869 & 0.0756 & 0.8143 \\
\hline $70 / 30$ & $9.2 / 90.8$ & 0.0075 & 23.0289 & 0.1661 & 0.0693 & 0.6846 \\
\hline $90 / 10$ & $7.3 / 92.7$ & 0.0089 & 114.287 & 1.0105 & 0.0651 & 0.8268 \\
\hline
\end{tabular}

flux and hence the methanol separation is more easier compared to toluene.

\subsubsection{Effect of Feed Composition}

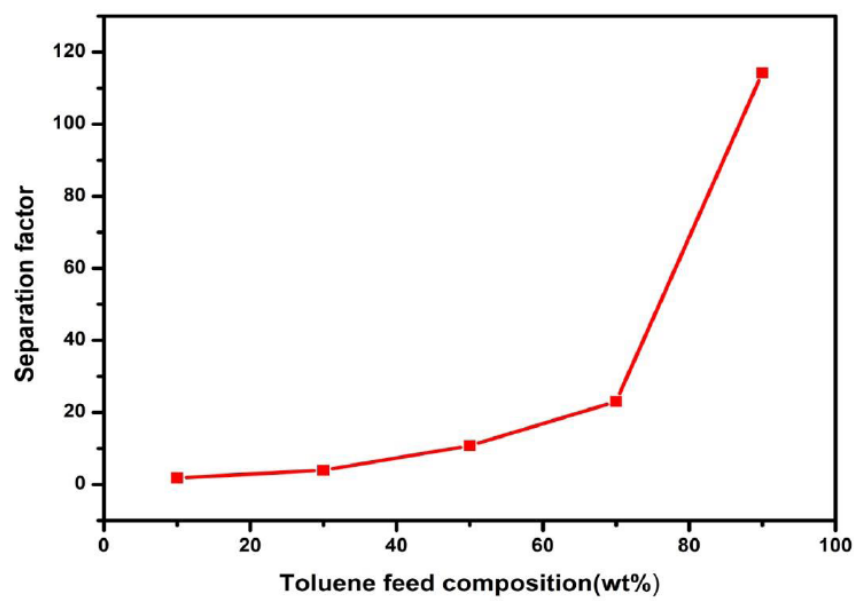

Figure 7: Variation of separation factor with toluene feed composition.
Figure 7 shows that separation factor increased with increasing toluene content in the feed. In the case of $10 / 90$ feed composition (10\% toluene and $90 \%$ methanol) the separation factor is 1.8045 . But in 90/10 feed composition there is a large increase observed in separation factor ie; 114.287. PSI shows almost an increasing tendency with increasing toluene concentration. Flux was not greatly influenced by feed concentration. The majority of total flux was for methanol than toluene. The separation factor increases with increase in concentration of toluene. As the feed contain higher concentration of toluene then the polymer membrane became more swollen, which helps in the easy passage of small methanol molecules through the membrane thereby increasing the methanol selectivity. Flux is also gradually increasing with increasing the toluene concentration.

In order to explain how the permeant passes through the membrane during pervaporation, a model of mass transport is used Figure $\mathbf{8}$. The most widely

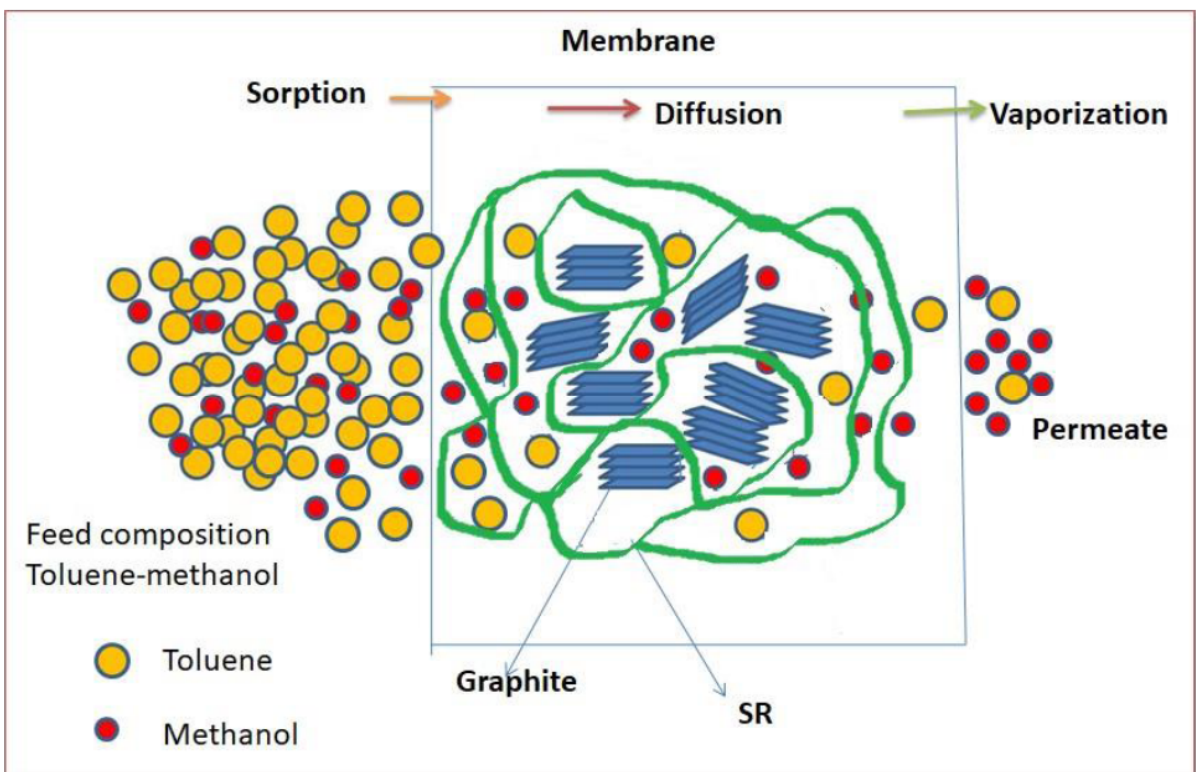

Figure 8: Schematic representation of pervaporation separation of organic mixtures through QM-graphite membrane. 
accepted model is the solution-diffusion model and based on this model, the movement of permeant from the feed (liquid phase) to the permeate (vapor phase) undergoes three consecutive steps: (a) sorption of permeate from the feed liquid to the membrane, (b) diffusion of permeate through the membrane, and (c) desorption of the permeate to the vapor phase

\section{CONCLUSION}

Silicone rubber graphite membrane was prepared by two roll mill mixing, followed by hot pressing on a hydraulic press at $150^{\circ} \mathrm{C}$. The XRD and SEM images confirmed the distribution and interaction of graphite layers and silicone rubber chains. The pervaporation result indicates that silicone rubber with $10 \mathrm{wt} \%$ graphite membrane showed a maximum enhancement in flux compared to neat silicone rubber membrane. But silicone rubber with $15 \%$ graphite membrane shows better separation factor than all other membrane. Methanol flux is contributing significantly towards the total flux. Flux and separation factor are increased with increase in toluene concentration in the feed. Study confirms that synthesized QMG composite membrane can successfully use for the separation of methanol from toluene/methanol mixture.

\section{ACKNOWLEDGMENTS}

The authors are grateful to Defence Research and Development Organization- (Order No. ERIP/ER/1504758/M/01/1667) New Delhi, India for providing the financial assistance.

\section{REFERENCES}

[1] Aouinti L, Denis Roizard and M. Belbachir. "PVC-activated carbon based matrices: A promising combination for pervaporation membranes useful for aromatic-alkane separations." Separation and Purification Technology 2015; 147: 51-61.

https://doi.org/10.1016/j.seppur.2015.04.007

[2] Ribeiro Cláudio P, Benny D. Freeman, Douglass S. Kalika and Sumod Kalakkunnath. "Aromatic polyimide and polybenzoxazole membranes for the fractionation of aromatic/aliphatic hydrocarbons by pervaporation." Journal of Membrane Science 2012; 390: 182-193. https://doi.org/10.1016/j.memsci.2011.11.042

[3] Li Zhansheng, Ben Zhang, Lianxu Qu, Jizhong Ren and Yang Li. "A novel atmospheric dielectric barrier discharge (DBD) plasma graft-filling technique to fabricate the composite membranes for pervaporation of aromatic/aliphatic hydrocarbons." Journal of Membrane Science 2011; 371: 163-170.

https://doi.org/10.1016/j.memsci.2011.01.035

[4] Kujawa Joanna, Sophie Cerneaux and Wojciech Kujawski. "Highly hydrophobic ceramic membranes applied to the removal of volatile organic compounds in pervaporation." Chemical Engineering Journal 2015; 260: 43-54.

https://doi.org/10.1016/j.cej.2014.08.092
[5] Ghoreyshi Ali Asghar, Hamidreza Sadeghifar and Fereshteh Entezarion. "Efficiency assessment of air stripping packed towers for removal of VOCs (volatile organic compounds) from industrial and drinking waters." Energy 2014; 73: 838843.

https://doi.org/10.1016/j.energy.2014.06.090

[6] Ray SK, Sawant SB, Joshi JB, Pangarkar VG. Development of new synthetic membranes for separation of benzenecyclohexane mixture by pervaporation-a solubility parameter approach, Ind. Eng. Chem. Res 1997; 36: 5265-5276 https://doi.org/10.1021/ie970351v

[7] Mohammadi AT, Matsuura T, Sourirajan S. Gas separation by silicone-coated dry asymmetric aromatic polyamide membranes, Gas. Sep. Purif 1995; 9: 181. https://doi.org/10.1016/0950-4214(95)98225-A

[8] Petersen J, Matsuda M, Haraya K. Capillary carbon molecular sieve membranes derived from Kapton for high temperature gas separation, J Membr Sci 1997; 131: 85. https://doi.org/10.1016/S0376-7388(97)00041-0

[9] Ji W, Sikdar SK. Pervaporation using adsorbent-filled membranes, Ind Eng Chem Res 1996; 35: 1124. https://doi.org/10.1021/ie9503609

[10] Lopez EC, Nevskaia DM, Muonz V, Rodrıguez-Ramos I, Guerrero-Ruiz A. Specific interactions between aromatic electrons of organic compounds and graphite surfaces as detected by immersion calorimetry, Langmuir 2004; 20: 1013.

https://doi.org/10.1021/la035349p

[11] Park HC, Meertens RM, Mulder MHV, Smolders CA. J Membr Sci 1994; 90: 265. https://doi.org/10.1016/0376-7388(94)80076-6

[12] Park HC, Meertens RM, Mulder MHV. Ind Eng Chem Res 1998; 37: 4408.

https://doi.org/10.1021/ie980117k

[13] Duval JM, Folkers B, Mulder MHV, Desgrandchamps G. CA. Sep. Sci Technol 1994; 29: 357. https://doi.org/10.1080/01496399408002488

[14] Ray S, Ray SK. Separation of organic mixtures by pervaporation using crosslinked rubber membranes, J Membr Sci 2006; 270: 132-145. https://doi.org/10.1016/j.memsci.2005.06.049

[15] Ray S, Ray SK. Separation of organic mixtures by pervaporation using crosslinked and filled rubber membrane, J Membr Sci 2006; 285: 108-119. https://doi.org/10.1016/j.memsci.2006.08.009

[16] Zhuang XJ, Chen XR, Su Y, et al. Improved performance of PDMS/silicalite-1 pervaporation membranes via designing new silicalite-1 particles. J Membr Sci 2015; 493: 37-45. https://doi.org/10.1016/j.memsci.2015.06.043

[17] Ikegami T, Negishi H, Sakaki K. Selective separation of $\mathrm{n}$ butanol from aqueous solutions by pervaporation using silicone rubber-coated silicalite membranes. J Chem Technol Biotechnol 2011; 86: 845-851.

https://doi.org/10.1002/jctb.2598

[18] Suhas DP, Aminabhavi TM, Raghu AV. Mixed matrix membranes of H-ZSM5-loaded poly(vinyl alcohol)used in pervaporation dehydration of alcohols: influence of silica/alumina ratio. Polym Eng Sci 2014; 54: 9. https://doi.org/10.1002/pen.23717

[19] Dong ZY, Liu GP, Liu SN, et al. High performance ceramic hollow fiber supported PDMS composite pervaporation membrane for bio-butanol recovery. J Membr Sci 2014; 450: 38-47. https://doi.org/10.1016/j.memsci.2013.08.039

[20] Molecular dynamics, grand canonical Monte Carlo and expert simulations and modeling of water-acetic acid pervaporation using polyvinyl alcohol/tetraethyl orthosilicates membrane, Journal of Molecular Liquids 2018; 265: 53-68. https://doi.org/10.1016/j.molliq.2018.05.078 
[21] Rezakazemi, Mashallah, Kazem Shahidi, and Toraj Mohammadi. "Synthetic PDMS composite membranes for pervaporation dehydration of ethanol." Desalination and Water Treatment 2015; 54: 1542-1549.

[22] Shahverdi, Mahnaz, Bahareh Baheri, Mashallah Rezakazemi, ElaheMotaee and Toraj Mohammadi.
"Pervaporation study of ethylene glycol dehydration through synthesized (PVA-4A)/polypropylene mixed matrix composite membranes." Polymer Engineering \& Science, 2013; 53:1487-1493.

https://doi.org/10.1002/pen.23406

Received on 10-02-2020

Accepted on 19-03-2020

Published on 27-03-2020

http://dx.doi.org/10.15379/2410-1869.2020.07.01.03

(C) 2020 Sarath et al.; Licensee Cosmos Scholars Publishing House.

This is an open access article licensed under the terms of the Creative Commons Attribution Non-Commercial License

(http://creativecommons.org/licenses/by-nc/3.0/), which permits unrestricted, non-commercial use, distribution and reproduction in any medium, provided the work is properly cited. 